\title{
Two Aberrant Splicings Caused by Mutations in the Insulin Receptor Gene in Cultured Lymphocytes from a Patient With Rabson-Mendenhall's Syndrome
}

\author{
Yoshihiko Takahashi, ${ }^{\ddagger}$ Hiroko Kadowaki, ${ }^{\star}$ Akifumi Ando, ${ }^{\ddagger}$ John D. Quin, ${ }^{\S}$ Angus C. MacCuish, ${ }^{\S}$ Yoshio Yazaki, ${ }^{\ddagger}$ \\ Yasuo Akanuma, ${ }^{*}$ and Takashi Kadowaki ${ }^{\ddagger}$ \\ *The Institute for Diabetes Care and Research, Asahi Life Foundation, Tokyo 100-0005, Japan; *Third Department of Internal Medicine, \\ Faculty of Medicine, University of Tokyo, Tokyo 113-0033, Japan; and ${ }^{\S}$ Stirling Royal Infirmary, Glasgow G31 2ER, United Kingdom
}

\begin{abstract}
Rabson-Mendenhall's syndrome is one of the most severe forms of insulin resistance syndrome. We analyzed an English patient described elsewhere and found novel mutations in both alleles of the insulin receptor gene. One is a substitution of $\mathrm{G}$ for $\mathrm{A}$ at the $\mathbf{3}^{\prime}$ splice acceptor site of intron 4, and the other is an eight-base pair deletion in exon 12. Both decrease mRNA expression in a cis-dominant manner, and are predicted to produce severely truncated proteins. Surprisingly, nearly normal insulin receptor levels were expressed in the patient's lymphocytes, although the level of expression assessed by immunoblot was $\sim 10 \%$ of the control cells. Insulin binding affinity was markedly reduced, but insulin-dependent tyrosine kinase activity was present. Analyzing the insulin receptor mRNA of the patient's lymphocytes by reverse transcription PCR, we discovered aberrant splicing caused by activation of a cryptic splice site in exon 5, resulting in a four-amino acid deletion and one amino acid substitution, but restoring an open reading frame. Skipped exon 5, another aberrant splicing, was found in both the patient and the mother who had the heterozygotic mutation, whereas activation of the cryptic splice site occurred almost exclusively in the patient. Transfectional analysis in COS cells revealed that the mutant receptor produced by cryptic site activation has the same characteristics as those expressed in patient's lymphocytes. We speculate that this mutant receptor may be involved in the relatively long survival of the patient by rescuing otherwise more severe phenotypes resulting from the complete lack of functional insulin receptors. (J. Clin. Invest. 1998. 101:588-594.) Key words: cryptic splice site • exon skipping • insulin binding - insulin resistance syndrome - polymerase chain reaction
\end{abstract}

\section{Introduction}

Rabson-Mendenhall's syndrome is characterized by marked insulin resistance, growth retardation, acanthosis nigricans,

\footnotetext{
Address correspondence to Takashi Kadowaki, M.D., Third Department of Internal Medicine, Faculty of Medicine, University of Tokyo, Tokyo 113-0033, Japan. Phone: +81-3-3815-5411 ext. 3111; FAX: +81-3-5689-7209.

Received for publication 23 July 1997 and accepted in revised form 24 November 1997.
}

J. Clin. Invest.

(C) The American Society for Clinical Investigation, Inc. 0021-9738/98/02/0588/07 \$2.00

Volume 101, Number 3, February 1998, 588-594

http://www.jci.org and a variety of inborn abnormalities somewhat similar to leprechaunism (1). Both of the syndromes are caused by mutations in the insulin receptor (IR) $)^{1}$ gene, and all the cases reported thus far are affected in both alleles of the IR gene (1-5). The patient we studied is an English patient with Rabson-Mendenhall's syndrome who had severe insulin-resistant diabetes (glycosylated hemoglobin, 14.2\%, and fasting immunoreactive insulin, $2442 \mathrm{pM}$ ), intermittent ketonuria, and was treated successfully with IGF-I (6). Although the other therapeutic agents were unsuccessful, the patient lived to age 13 when he started subcutaneous IGF-I injection. Analysis of the patient's EB virus-transformed lymphocytes revealed markedly reduced $\left[{ }^{125} \mathrm{I}\right]$ insulin binding, which was typical of the syndrome. We performed PCR-direct sequencing analysis with the patient's genomic DNA from his lymphocytes. One allele had a substitution of $\mathrm{G}$ for $\mathrm{A}$ at the $3^{\prime}$ splice acceptor site in intron 4 (-AG-exon5- $\rightarrow$-GG-exon5-), and the other had an eight-basepair deletion in exon 12, causing a premature termination at codon 801 (7). Sequencing of the parent's genomic DNA revealed that the former mutation was inherited from the mother, and the latter from the father. Since we could not detect any other mutations in the coding regions and exonflanking regions, at first we expected the mutation in intron 4 would cause skipping of exon 5, and both of the mutations would cause frameshifts and create premature stop codons that would produce no functional IR. Surprisingly, immunoblot analysis revealed that almost normal-sized insulin proreceptor, and probably the mature receptor as well, were expressed in the patient's transformed lymphocytes. This result urged us to study mRNA of the patient's IR gene expressed in lymphocytes, and to investigate the expression of each allele in the patient's and the parents' lymphocytes.

\section{Methods}

Immunoblot analysis and insulin-binding assay. In EB virus-transformed lymphocytes, $\sim 2 \times 10^{7}$ cells were lysed in a buffer containing 1\% Triton X-100, 50 mM Hepes pH 7.4, 10 mM EDTA, 1 mM PMSF, and aprotinin. The lysates were immunoprecipitated with a monoclonal antibody against IR ( $\alpha$ IR- 1$)$, anti-mouse IgG polyclonal antibody, and protein A. The precipitates were washed with lysis buffer containing $0.3 \mathrm{M} \mathrm{NaCl}$, and were boiled in Laemmli's sample buffer containing 2-mercaptoethanol for $6 \mathrm{~min}$. Immunoblotting was performed by a standard protocol using polyclonal antibody raised against a COOH-terminal peptide of IR $(\alpha \mathrm{IRC} ; 8)$. Insulin-binding assay was performed as previously described (9).

Immune-complex kinase assay. Immunoprecipitates containing IRs from each cell line were prepared as described above, washed once with kinase buffer containing $0.1 \%$ Triton, $50 \mathrm{mM}$ Hepes $\mathrm{pH} 7.4$,

1. Abbreviations used in this paper: CFTR, cystic fibrosis transmembrane conductance regulator; IR, insulin receptor; RT, reverse transcriptase. 
$10 \mathrm{mM} \mathrm{MgCl} 2,2 \mathrm{mM} \mathrm{MnCl}$, and $1 \mathrm{mM} \mathrm{Na}_{3} \mathrm{VO}_{4}$, resuspended in $50 \mu \mathrm{l}$ of the kinase buffer, and kept on ice until reaction time. In autophosphorylation analysis, the immune complex was treated with various concentrations of insulin for $20 \mathrm{~min}$ at room temperature, and then incubated with $50 \mu \mathrm{M}$ of unlabeled ATP and $10 \mu \mathrm{Ci}$ of $\gamma$ - $\left[{ }^{32} \mathrm{P}\right]$ ATP for a further $20 \mathrm{~min}$. The reaction was stopped by adding Laemmli's sample buffer with 2-mercaptoethanol and boiling for $6 \mathrm{~min}$. In tyrosine kinase assay, insulin treatment was performed in the same manner, and the sample was incubated with $50 \mu \mathrm{M}$ of unlabeled ATP and $10 \mu \mathrm{Ci}$ of $\gamma-\left[{ }^{32} \mathrm{P}\right] \mathrm{ATP}$ for $6 \mathrm{~min}$. Then, $10 \mu \mathrm{g}$ of histone H2B was added and the sample was further incubated for $10 \mathrm{~min}$. The stop reaction was the same as described above. The samples were subjected to SDS-PAGE, and the gel was fixed and treated for $1 \mathrm{~h}$ in $1 \mathrm{~N} \mathrm{KOH}$ at $55^{\circ} \mathrm{C}$ for hydrolysis. The gel was dried and subjected to autoradiography $(9,10)$.

Reverse transcription (RT)-PCR analyses. Total RNA was extracted from transformed lymphocytes by the acid-guanidine phenolchloroform method. IR cDNA was generated by M-MLV reverse transcriptase (United States Biochemical Corp., Cleveland, Ohio) using a specific antisense primer located in exon 19 of IR gene (5'-ATC TGA ATC ATC TCT TGA AG-3'; 11), since sequencing analysis of genomic DNA and the study of the receptor expressed in the patient's cells strongly suggested that the structure of the tyrosine kinase domain of the expressed receptor was normal. Sequences of the primers used in the following analyses were indicated in Table I.

Each cDNA strand generated from $0.5 \mu \mathrm{g}$ of total RNA was used for PCR. Most of the reactions were performed under the following conditions: $94^{\circ} \mathrm{C}, 1 \mathrm{~min} ;-60^{\circ} \mathrm{C}, 1 \mathrm{~min} 30 \mathrm{~s} ;-72^{\circ} \mathrm{C}, 1 \mathrm{~min} 30 \mathrm{~s} ; 40 \mathrm{cy}-$ cles. $\mathrm{pSV}_{2} \mathrm{hIR}$, an expression vector carrying normal IR cDNA (Ullrich's type; 12), was used as a control template for most of the reactions since the IR expressed in lymphocytes is Ullrich's type and does not contain exon 11. In all RT-PCR reactions, a sample without template was used as a negative control.

Subcloning of RT-PCR products. RT-PCR products were subcloned into $\mathrm{pCR}^{\mathrm{TM}}$-II vector (TA cloning kit; Invitrogen Corp., San Diego, CA) and sequenced. Products spanning exons 10-13 were difficult to subclone, and therefore second amplification spanning the $3^{\prime}$ terminus of exons $10-12$ or spanning exon 12 to the $5^{\prime}$ terminus of exon 13 was performed, and the products were subcloned.

Allele-specific oligonucleotide hybridization. Allele-specific oligonucleotide hybridization was performed as described, with one exception (13). Hybridization for detecting cryptic acceptor site selection and skipping exon 5 was performed in the following steps: the filter was probed with ${ }^{32} \mathrm{P}$-labeled oligonucleotide corresponding to cryptic acceptor site selection for $6 \mathrm{~h}$, washed in $5 \times$ SSPE $0.1 \%$ SDS at $60^{\circ} \mathrm{C}$ for $10 \mathrm{~min}$, and then probed with the same amount of ${ }^{32} \mathrm{P}$-labeled oligonucleotide corresponding to the skipping of exon 5. This procedure made mRNA expression from the maternal allele clear.

Transient expression study of mutant receptor. One of the clones with mutant cDNA spanning exons 4-7 had only two silent misincorporated bases that did not change the amino acids. Therefore, the Sac I-Bgl I fragment from the subcloned cDNA was prepared and ligated both with EcoRV-Sac I fragments and Bgl I-Bam HI fragments from normal IR cDNA into pBluscript (EcoRV-Bam HI). The obtained EcoRV-Bam HI fragment was checked by sequencing and enzyme digestion, and was ligated with the BamHI-SpeI fragment of IR cDNA into the expression vector.

Transfection into COS 1 cells was done by the calcium phosphate method (14). Immunoblot analysis and immune complex assays were performed as described above. Quantification of radioactivity in all experiments was performed by Fuji BAS 2000 image analyzer.

\section{Results}

Studies on transformed lymphocytes. First we characterized the IR expressed in the patient's lymphocytes. Insulin binding in intact cells was markedly decreased in the patient (Fig. $1 A$ ). Immunoblot analysis revealed that almost normal sizes of insulin proreceptor and $\beta$ subunit of IR were expressed in the patient's cells, and the ratio of the proreceptor $/ \beta$ subunit of IR was $\sim 1: 1$, whereas the ratio was $<1: 8$ in control cells and in the parents' cells. This result suggested the existence of the defect on processing, or an increase in receptor degradation (Fig. $1 B$ ). Quantification of the $95-\mathrm{kD} \beta$ subunit on the blot (Fig. $1 B$ ) by BAS 2000 image analyzer revealed that its relative expression level per lymphocyte was $\sim$ 10:1:5:5 (control/patient/father/mother). Thus, expression of the insulin receptor was markedly reduced in the patient, and was mildly decreased in both of parents. Specific insulin binding of the patient's receptor in immune complex or wheatgerm agglutinin-agarose fraction was almost undetectable when the same amount of the wild-type receptor assessed by the amount of $95-\mathrm{kD} \beta$ subunit on Western blotting had $5-10 \%$ binding (data not shown). Therefore, severely decreased insulin binding in the patient's lymphocytes was due to decreased expression of mature receptor and the decreased insulin-binding affinity of the receptor.

Autophosphorylation and tyrosine kinase activity of the patient's receptor was so much reduced when the same amount of wild-type receptor and patient's receptor were used that dose-dependent activation of tyrosine kinase of the patient's receptor was not clearly observed (data not shown). When a fivefold excess of the patient's receptor was used (Fig. 2, $A$ and $B$ ), however, insulin-dependent autophosphorylation and tyrosine kinase activity in IR-1 immunoprecipitates were actually observed, and the dose response was shifted to the right, probably because of the decreased affinity for insulin. To exclude the artifacts of the used antibody ( $\alpha$ IR- 1$)$, immune complex assays using polyclonal antibody $\alpha$ IRC were also performed, and the results above were confirmed (data not shown). Since $\alpha$ IRC antibody does not cross-react with IGF-I receptor

Table I. Sets of Oligonucleotides Used in the Experiments

\begin{tabular}{|c|c|c|}
\hline PCR primer (spanning region) & Upstream primer (sense) & Downstream primer (antisense) \\
\hline Exon 4-exon 7 & 5'ATTCCAGCAACTTGCTGTGC3' & 5'TTTGTAGAACAGCATGAACC 3' \\
\hline Exon 10-exon 13 & 5'CCATTCGAGTCTGAAGATTC 3' & 5'GACACCAGAGCGTAGGATCG3' \\
\hline Exon 10-exon 12 (second amplification) & 5'GGATTACCTGCACAACGTGG3' & 5'GGTCCTCGCACTGACGTAGG3' \\
\hline Exon 12-exon 13 (second amplification) & 5'ATGTTGGGAATGTGACGGTG3' & 5'GCGTCACAGGGCCAACAATG3' \\
\hline Allele-specific oligonucleotide probe & Wild-type & Mutant-type \\
\hline Acceptor site selection & 5'CGAGGAGGCAACAATCTGGC 3' (45N) & 5'CGAGGAGGCACTGAGCTAGA3' (45M) \\
\hline Skipping of exon 5 & none & 5'CGAGGAGGCAGAACTACTCC 3' (46S) \\
\hline Exon 12 (with or without eight-basepair deletion) & 5'CAGGCTTGCAACCAGGACA3' & 5'CAGGCTTGCAACCCCTGAG3' \\
\hline
\end{tabular}



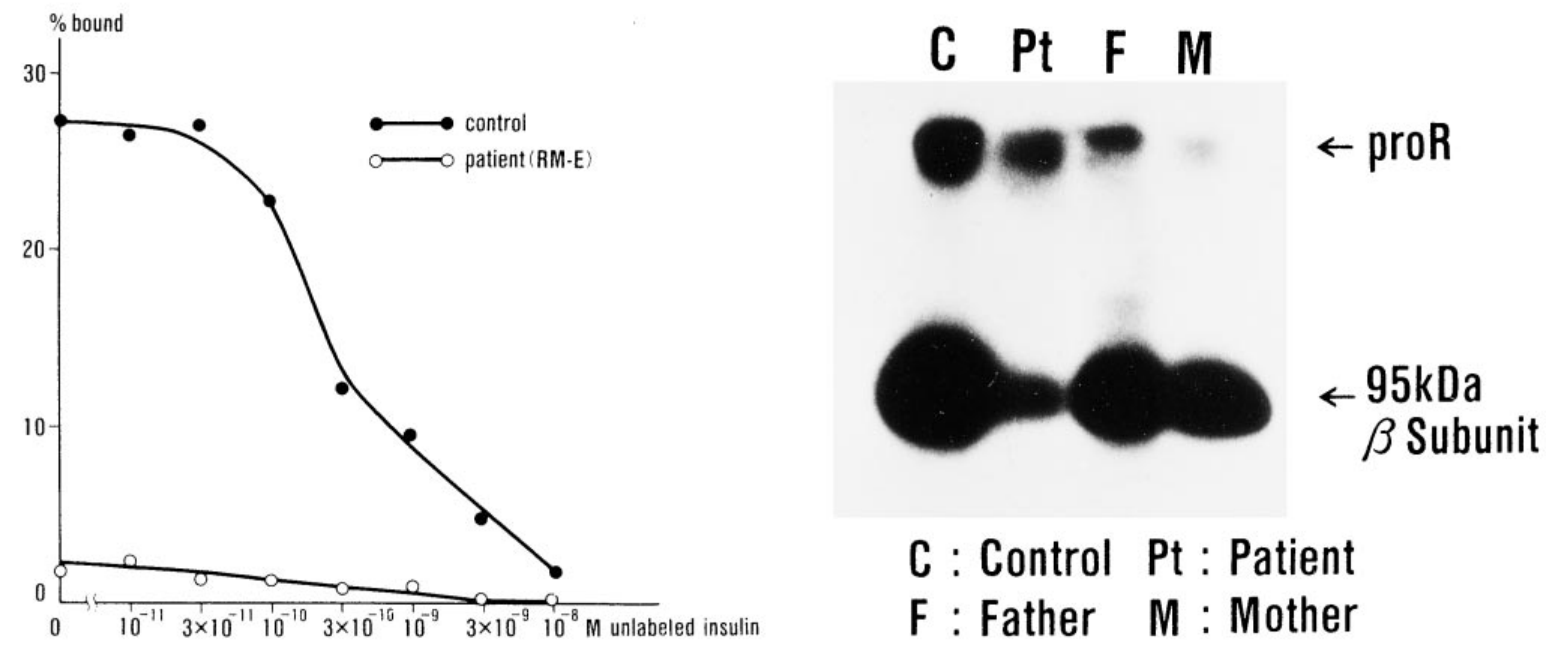

Figure 1. Insulin binding and insulin receptor expression in EB virus-transformed lymphocytes. $A$ shows the insulin binding in intact transformed lymphocytes of the patient and a normal subject. $B$ shows the immunoblot analysis for quantification of expressed insulin receptor. The electrophoresis was performed in a reducing condition, and proreceptor $(190 \mathrm{kD})$ and $\beta$ subunit of the mature receptor $(95 \mathrm{kD})$ were visualized. In most of the quiescent lymphocytes from normal subjects, the amount of proreceptor was less than one-eighth that of the mature receptor. $C$, normal control subject; $P t$, patient; $F$, father; $M$, mother.

(8), these observations were not due to contamination of IGF-I receptor in the immunoprecipitates.

Structure of mRNAs encoding mutant insulin receptors. To analyze the primary structure of the IR expressed in the patient's lymphocytes, we examined mRNA expressed in the lymphocytes by use of the RT-PCR method.

First, we subcloned RT-PCR products spanning exons 4-7 because aberrant splicing due to the nucleotide substitution in intron 4 was the most probable mechanism of the receptor expression. Sequencing analysis revealed that the presence of three kinds of mRNA generated from the patient's IR gene.
One had a complete normal sequence in exons 4-7, but the others were aberrantly spliced: one was spliced into mRNA shortened by 12 bases at a cryptic acceptor site at the $5^{\prime}$ terminus of exon 5, and the other had skipped exon 5. The exon skipping creates a premature stop codon at position 341, and causes the truncation of $\alpha$ subunit. The aberrant splicing by activation of the cryptic acceptor site results in a substitution of Thr for Asn at position 348 and deletion of the subsequent four amino acids (Fig. 3), but does not create any premature stop codon. Considering the known mutations on splice donor sites or acceptor sites (15), normal splicing on this region
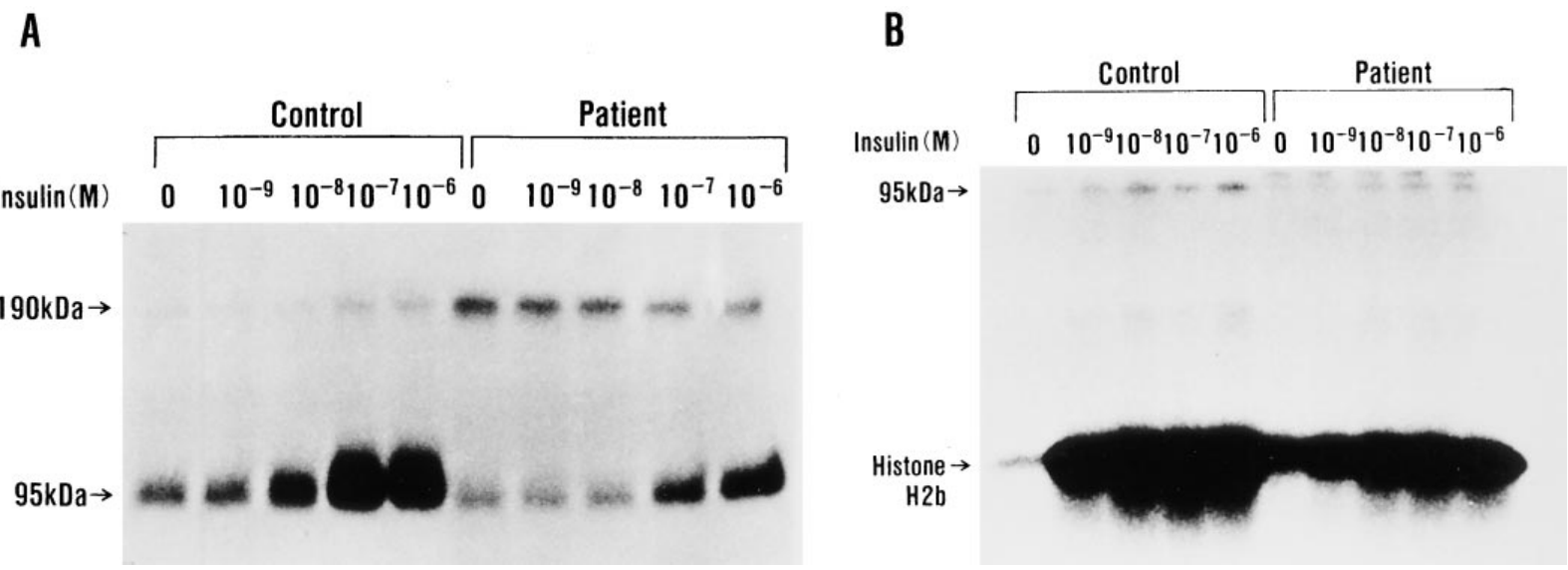

Figure 2. Immune complex kinase assays in transformed lymphocytes. (A) Autophosphorylation of the receptor. (B) Tyrosine kinase activity. It should be noted that in both of the experiments the receptor of the patient's was about fivefold excessive to that of the control's (confirmed by immunoblot analysis, not shown) for more sensitive detection of dose-dependent changes. In these two experiments, the dose response of autophosphorylation of the $95-\mathrm{kD} \beta$ subunit and of the tyrosine kinase activity was markedly shifted in the patient, but the maximal activity at $10^{-6} \mathrm{M}$ insulin in the patient reached about one-half of the maximal response in the control. Autophosphorylation of $190 \mathrm{kD}$ proreceptor was observed in the patient and the control $(A)$. 

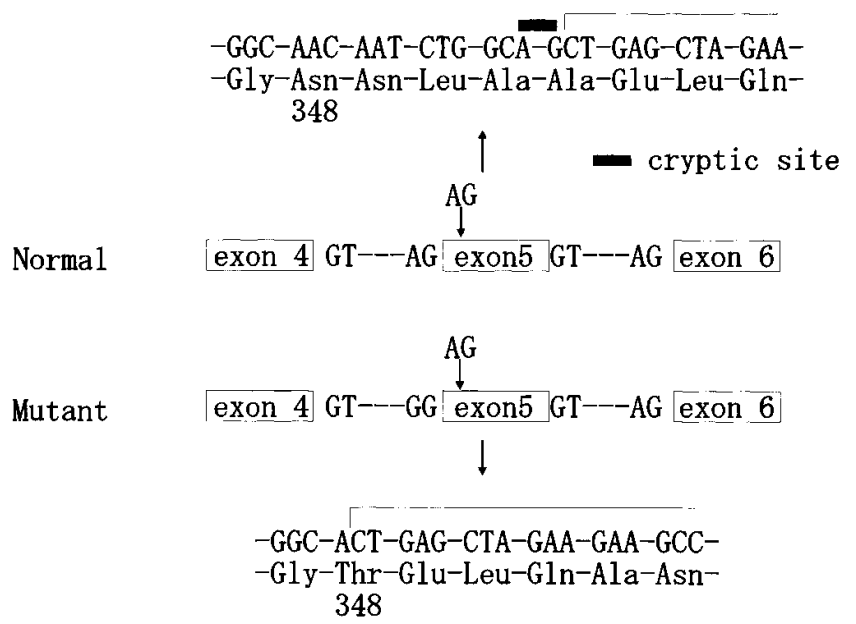

Figure 3. Structure of mutant insulin receptor. The scheme shows the structure of the normal cDNA and the aberrant cDNA with 12-basepair skipping. The skip was caused by the cryptic splice site selection in exon 5 (-ACAATCTGGCAGCTGAGCTA-) and resulted in one amino acid substitution (Asn348 $\rightarrow$ Thr) and four-amino acid deletion (Asn-Leu-Ala-Ala) and in normal translation in the subsequent codons.

would be from the paternal allele, and the latter two aberrant splicings would be from the maternal allele that has a point mutation at a splice acceptor site in intron 4.

Next we performed RT-PCR spanning exons 10-13, generating cDNAs with $\sim 500 \mathrm{bp}$ in the patient and the control. Thus, exon skipping or major insertion of cryptic exons could be ruled out in this region. Since it was hard to subclone the RT-PCR products spanning exons 10-13, we carried out second amplifications with specific internal primers as described in Methods. The length of second amplification products spanning exons 10-12 indicated they did not contain exon 11, which is a predominant form in lymphocytes (data not shown). Thus, the property of tissue-specific alternative splicing in the IR gene was preserved in the patient's lymphocytes. Second amplification spanning exons 12-13 and its subcloning revealed that splicing around exons 12-13 was not altered in the patient (data not shown). Therefore, an eight-basepair deletion in exon 12 was considered to create a premature stop codon at 801 in exon 12.

The $m R N A$ expression level of the maternal allele $(A G \rightarrow$ $G G$ in intron 4$)$ and the paternal allele ( $\Delta 8 b p$ in exon 12$)$. We further investigated mRNA expression in lymphocytes of the family to find out whether there is any difference in splicing among the simple heterozygotes and the compound heterozygote. In this ASO study, the amount of RT-PCR products was normalized by ethidium bromide staining. Fig. 4 shows that the oligonucleotide probe corresponding to the skipping of exon 5 was hybridized with the patient's and the mother's (indicated as $46 \mathrm{~S}$ ) cDNA, indicating that exon skipping occurred almost exclusively in the patient's and the mother's cells, both of which had the mutation in intron 4. Surprisingly, hybridization with the oligonucleotide corresponding to the cryptic acceptor site selection was observed almost exclusively in the patient's cDNA (indicated as $45 \mathrm{M}$ ). When the amount of the fragment with skipping of exon 5 was considered as an internal control of the expression of maternal allele with the splice acceptor site mutation, the result suggested that activation of the cryptic acceptor site in exon 5 hardly occurred in the mother who was a simple heterozygote for the splice acceptor site mutation. RT-PCR spanning exons 10-13 followed by allele-specific oligonucleotide hybridization (ASO) analysis revealed that $\Delta 8$-bp expression in the father was detectable, but was strikingly decreased when compared with the expression of wild-type allele (data not shown). Thus, $\Delta 8$ bp in exon 12 severely decreased mRNA expression in a cis-dominant manner. In the patient, $\Delta 8$-bp expression was also detectable, and the amounts of transcript from the maternal allele and the paternal allele appeared approximately equal (data not shown).

Transient expression into COS1 cells. To confirm that the obtained primary structure was just one of the IR immunologically detected in the patient's lymphocytes, we constructed the expression vector of the mutant IR and performed transfectional analyses. Cells on each $10-\mathrm{cm}$ dish were prepared for immune complex binding, immunoblotting, or immune complex kinase assay. Fig. 5 shows representative data of insulin binding in immune complexes and the amount of receptor in corresponding immune complexes. Monoclonal antibody IR-1 could not distinguish the transfected IR from native IR of COS, so the values of insulin binding were the sums of those of transfected IR and native IR contained in immune complexes. The amount of antibody used was enough for complete immunoprecipitation of expressed receptor.

When the same amount of wild-type IR cDNA or mutanttype cDNA was transfected (Fig. $5 \mathrm{~A}$ ), the level of overexpressed proreceptor was the same, but the amount of $\beta$ subunit of mature receptor was markedly decreased in mutant receptor immune complex. The increase in the ratio of the proreceptor-receptor $\beta$ subunit may reflect the defect in receptor processing on the basis of known mutations in the $\alpha$ subunit of IR. Insulin binding in the immune complex of the mutant plus native COS receptor was almost the same as that of the untransfected COS receptor (Fig. $5 \mathrm{~A}$, right). When wild-type cDNA or fivefold excessive amount of the mutant cDNA was transfected (Fig. $5 \mathrm{~B}$ ), the amount of the expressed mutant

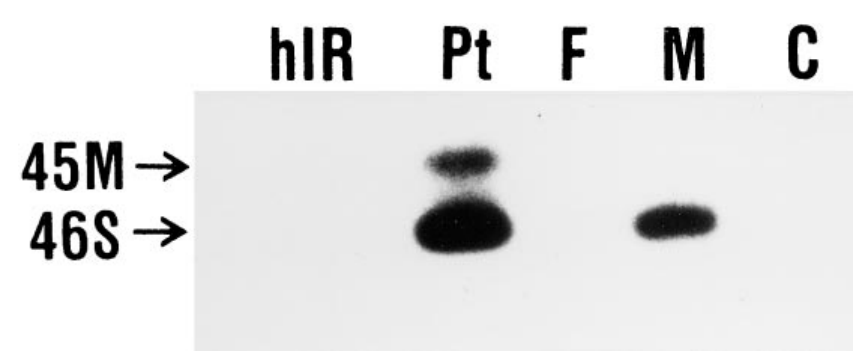

Figure 4. Oligonucleotide hybridization study for RT-PCR products spanning exons 4-7. In this experiment, two kinds of probes were simultaneously hybridized to the RT-PCR products to visualize expression of cryptic site-activated product (indicated as $45 \mathrm{M}$ ) and the exon-skipped product (indicated as 46S) in the same autoradiography. Skipping of exon 5 was found both in the patient and the mother, but the activation of cryptic acceptor site was found only in the patient. $C$, normal subject; $P t$, patient; $F$, father; $M$, mother; $h I R$, pSV2hIR (as a control). 

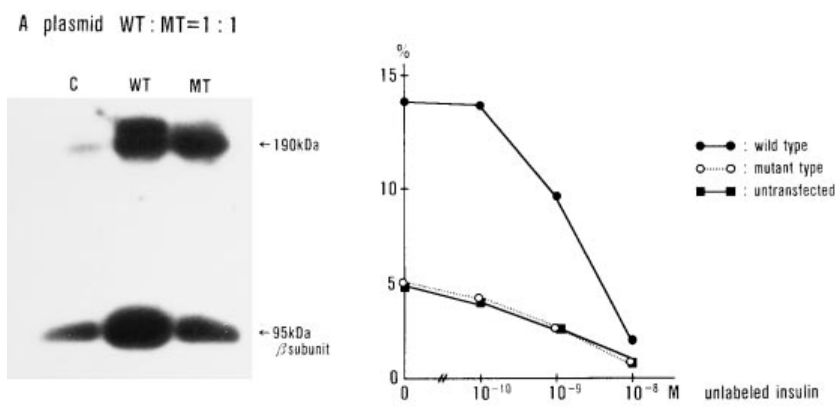

B plasmid $W T: M T=1: 5$
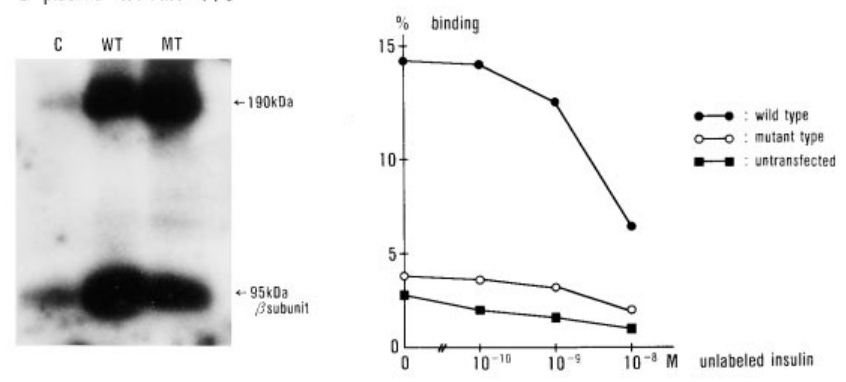

Figure 5. Transient expression of the mutant receptor in COS 1 cells. $A$ and $B$ show immune complex insulin binding assay (right) and quantification of insulin receptor contained in each immune complex (left). $2 \mu \mathrm{g}$ of wild-type expression vector $(A, B)$ and $2(A)$ or $10 \mu \mathrm{g}(B)$ of mutant-type vector were transfected into COS 1 cells. The amount of the mature receptors contained in each immune complex was assessed by immunoblotting. $C O S$, untransfected; $W T$, wildtype; $M T$, mutant type. Experiment $A$ suggested that the mutant receptor had received abnormal processing or degradation, and insulin binding of untransfected, wild-type, and mutant type was $4.7 \%$, $13.4 \%$, and $4.7 \%$, respectively. Experiment $B$ showed that the mutant receptor had significantly lower insulin binding than expected from immunoblotting: immunoblot analysis revealed that the mutant receptor was expressed about threefold of the native receptor, while insulin binding of the untransfected, wild-type, and mutant type was $2.6 \%, 14.2 \%$, and $3.8 \%$, respectively.

proreceptor was larger than that of wild-type proreceptor. Also, expression of the mutant mature receptor increased, and when the amount of native COS receptor was subtracted, the amount of expressed mutant receptor was estimated to be approximately twofold that of native COS receptor. Similarly, the amount of expressed wild-type mature receptor (Fig. $5 \mathrm{~B}$ ) was estimated to be approximately fourfold of the native receptor in COS. Thus, the ratio of the expressed mutant and wild-type receptor was $\sim 1: 2$. As the bound/free value in the insulin-binding study was proportional to the amount of IR, however, the ratio must be 1:8. Therefore, these data suggested that the mutant receptor was decreased in insulin-binding affinity. Transfectional analysis of mutant cDNA in an excess of fivefold to the wild-type cDNA revealed that the mutant receptor had insulin-dependent tyrosine kinase, although the dose response appeared to be shifted to the right (data not shown). Thus, the characteristics of the receptor expressed in the patient's lymphocytes such as impaired processing, decreased insulin binding affinity, and preserved tyrosine kinase activity were confirmed in the transfectional analysis.

\section{Discussion}

Our patient with Rabson-Mendehall's syndrome has an eightbasepair deletion in exon 12 of the paternal allele, and a missense mutation at splice acceptor site of intron 4 in the maternal allele of the insulin receptor gene. The study described above demonstrated that eight basepair deletions in exon 12 in the paternal allele did not produce any functional insulin receptor, whereas the missense mutation at splice acceptor site of intron 4 in the maternal allele caused exon skipping and in part activation of a cryptic acceptor site on exon 5 resulting in production of an abnormal insulin receptor with an altered subunit and a conserved subunit. This cryptic splice site activation was responsible for expression of an abnormal insulin receptor in patient's lymphocytes. Expression of the receptor in lymphocytes decreased to one-tenth of that of control cells. Its insulin-binding affinity was also severely reduced, and thus insulin binding in the patient's transformed lymphocytes decreased to $\sim 1 / 20$ of that of control cells. Tyrosine kinase activity of the abnormal insulin receptor was present because of the preserved subunit.

Mutations in consensus sequences of introns are known to result in aberrant splicings. Such mutations cause exon skipping, activation of a cryptic site, creation of a pseudoexon within an intron, and intron retention to redefine exon-intron structures (15). Those mutations are mainly discovered in $\beta$-globin gene, although in many of the studies the in vitro splicing system in yeast was used to analyze the pattern of aberrant splicing. As for nonsense mutations, recent reports have focused on mRNA expression in patients' cells, and exon skippings caused by nonsense mutations have been reported. One of the interesting reports has indicated that nonsense mutation E92X on cystic fibrosis gene (CFTR) causes exon skipping in patients' lymphocytes, but insertion of cryptic exon as well as exon skipping occurs in patients' nasal epithelial cells (16). This result suggests that different regulation of splicing with mutations in genomic DNA occurs in a tissue-specific manner as does alternative splicing with normal genomic DNA. Another report described exon skippings caused by nonsense mutations in several diseases, and in some cases, exon skipping restored an open reading frame because of the sequence of the neighboring exons (17). To our knowledge, however, characterization of the mutation in both alleles, the synthesized protein, and the comparison of the parents have rarely been reported.

We clarified the difference in mRNA expression of simple heterozygotes and the compound heterozygote (patient), and also characterized the mutant protein caused by cryptic acceptor site activation. In our study, the aberrant splicing was actually detected in in vitro culture of human cells, and one of the interesting findings is that the cryptic acceptor site was activated almost exclusively in the patient's cells that cannot produce normal IR. Based upon the parents' analysis, both the missense mutation in intron 4 and the deletion in exon 12 cause mild or severe decrease in mRNA. In addition, skipping exon 5 from the maternal allele or $\Delta 8$ bp in exon 12 from the paternal allele causes severe truncation of the receptor protein which has no function because of lack of the transmembrane and kinase domain. Thus, the cryptic site activation appeared to be some compensation for the patient. Although we did not perform Northern blot analysis, it was clear that no small amount of the aberrant mRNA through this cryptic site activation was produced in terms of the expression level of the mu- 
tant receptor, despite the high possibility of its processing defect (Fig. 1). Transfectional analysis in COS cells confirmed that the subcloned mutant receptor is really the one that was detected in the patient's cells.

The mechanism for activation of cryptic acceptor site found in the patient, not in the mother, remains unclear. Several agonistic and antagonistic splicing factors have been described to alter splice site selection (18-20), and they may really alter splice site selection in the patient's cells. It cannot completely be ruled out that selection of clones in in vitro lymphocyte culture occurred and the clone with the activation of the cryptic site in the IR gene had some advantage for survival in culture. However, in contrast to another patient with homozygous nonsense mutation (21) or other reported patients with leprechaunism, the patient lived relatively long (13 yr) until he received IGF-I treatment for the first time. Thus, it is possible that the mutant (or redefined) IR actually worked in the patient. For example, a patient with a homozygous nonsense mutation in the CFTR gene (R1162X) has been reported to have no reduction in CFTR mRNA in respiratory tissue, which can explain the patient's mild pulmonary illness (22). Thus, in some cases compensatory regulation of mRNA expression may work in vivo, and may partially rescue the phenotype. Winnard et al. have suggested that a new initiation in a large deletion of exons or activation of a cryptic splice site in a nonsense mutation in dystrophin gene may redefine ORF(s) and produce dystrophin in patients with Duchenne's muscular dystrophy (23). Taken together, variable compensatory mechanisms may work in patients with genetic diseases, and in some cases it may be significant for phenotypic rescue.

The IR expressed in the patient's lymphocytes has a novel in-frame mutation. The mutation lies in the $\mathrm{COOH}$-terminal side of the cysteine-rich domain in the $\alpha$ subunit, and the binding affinity for insulin was markedly decreased. Tyrosine kinase activity was present, though it was reduced, and the regulatory region including $\mathrm{Tyr}^{960}$ (the numbering is from the cited papers, according to Ullrich's type of IR) was preserved (24, $25)$. Considering a reported mutation $\left(\mathrm{Ser}^{323} \rightarrow \mathrm{Leu}\right)$ that also lies in the COOH-terminal side of the domain, and selectively impairs insulin binding (26), the mutant receptor in the patient may have insulin action if it is exposed to high concentrations of insulin. Also, the increased ratio of proreceptor/receptor $\beta$ subunit highly suggests a defect in receptor processing. $\mathrm{Ser}^{323} \rightarrow$ Leu mutation does not impair receptor processing, and the difference may rise from larger structural changes in our patient's four-amino acid deletion and one amino acid substitution.

Because IR is known to bind IGF-I with a lower affinity, the fact that the patient was efficiently treated with IGF-I raises the question whether the therapeutic effect of recombinant human IGF-I is mediated by the IGF-I receptor or by the mutant IR in this patient. Additional experiments demonstrated that specific [ $\left.{ }^{125} \mathrm{I}\right] \mathrm{IGF}-\mathrm{I}$ binding in anti-IR immune complex from the patient's cells was not detectable when $4-8 \%$ binding was observed in the immunoprecipitates from control cells. In contrast, [ $\left.{ }^{125} \mathrm{I}\right] \mathrm{IGF}-\mathrm{I}$ binding in the patient's intact lymphocytes was $5.6 \%$ in a representative experiment. These findings indicate that the mutant IR of the patient is defective in IGF-I binding as well as insulin binding, and the IGF-I receptor expression is not impaired in the patient. In addition, anti-IR immune complex kinase assay revealed that IGF-I-induced autophosphorylation of the normal IR was clearly observed, but that of the mutant receptor was undetectable (data not shown). Therefore, we speculate that the therapeutic effect of IGF-I is mediated mainly via IGF-I receptor in the patient (10).

In conclusion, we discovered novel mutations in the IR gene, one of which resulted in activation of a cryptic acceptor site and production of an abnormal but partially active IR with a novel in-frame mutation. Interestingly, activation of the cryptic site was not detected in the parents or a normal subject, and it may be involved in partial rescue of the patient's life.

\section{References}

1. Taylor, S.I. 1992. Molecular mechanism of insulin resistance. Lessons from patients with mutations in the insulin receptor gene. Diabetes. 41:14731490.

2. Flier, J.S. 1992. Syndromes of insulin resistance. From patient to gene and back again. Diabetes. 41:1207-1219.

3. Moller, D.E., and J.S. Flier. 1991. Mechanism of disease: insulin resistance mechanisms, syndromes, and implications. N. Engl. J. Med. 325:938-948.

4. O'Rahilly, S., and D.E. Moller. 1992. Mutant insulin receptors in syndromes of insulin resistance. Clin. Endocrinol. 36:121-132

5. Kadowaki, T., C.L. Bevins, A. Cama, K. Ojamaa, B. Marcus Samuels, H. Kadowaki, L. Beitz, C. McKeon, and S.I. Taylor. 1988. Two mutant alleles of the insulin receptor gene in a patient with extreme insulin resistance syndrome. Science. 240:787-790.

6. Quin, J.D., B.M. Fisher, K.R. Paterson, A. Inoue, G.H. Beastall, and A.C. MacCuish. 1991. Acute response to recombinant insulin-like growth factor-I in a patient with Mendenhall's syndrome. N. Engl. J. Med. 323:1425-1426.

7. Kadowaki, H., Y. Takahashi, A. Ando, K. Momomura, Y. Kaburagi, J.D. Quin, A.C. MacCuish, N. Koda, Y. Fukushima, S.I. Taylor, et al. 1997. Four mutant alleles of the insulin receptor gene associated with genetic syndromes of extreme insulin resistance. Biochem. Biophys. Res. Commun. 237:516-520.

8. Izumi, T., Y. Saeki, Y. Akanuma, F. Takaku, and M. Kasuga. 1988. Requirement for receptor-intrinsic tyrosine kinase activities during ligand-induced membrane ruffling of KB cells. J. Biol. Chem. 263: 10386-10393.

9. Yamamoto, R., T. Shiba, K. Tobe, Y. Shibasaki, O. Koshio, T. Izumi, M. Odawara, Y. Mikami, N. Matsuura, Y. Akanuma, et al. 1990. Defect in tyrosine kinase activity of the insulin receptor from a patient with insulin resistance and acanthosis nigricans. J. Clin. Endocrinol. Metab. 70:869-878.

10. Takahashi, Y., H. Kadowaki, K. Momomura, Y. Fukushima, T. Orban, T. Okai, Y. Taketani, Y. Akanuma, Y. Yazaki, and T. Kadowaki. 1997. A homozygous kinase-defective mutation in the insulin receptor gene in a patient with leprechaunism. Diabetologia. 40:412-420.

11. Seino, S., M. Seino, S. Nishi, and G.I. Bell. 1990. Human insulin receptor gene: partial sequence and amplification of exons by polymerase chain reaction. Diabetes. 39:123-128.

12. Ullrich, A., J.R. Bell, E.Y. Chen, R. Herrera, L.M. Petruzzelli, T.J. Dull, A. Gray, L. Coussens, Y.C. Liao, M. Tsubokawa, et al. 1985. Human insulin receptor and its relationship to the tyrosine kinase family of oncogenes. Nature. 313:756-761.

13. Kadowaki, T., H. Kadowaki, and S.I. Taylor. A nonsense mutation causing decreased levels of insulin receptor mRNA: detection by a simplified technique for direct sequencing of genomic DNA amplified by polymerase chain reaction. Proc. Natl. Acad. Sci. USA. 87:658-662.

14. Kaburagi, Y., K. Momomura, R. Yamamoto-Honda, K. Tobe, Y. Tamori, H. Sakura, Y. Akanuma, Y. Yazaki, and T. Kadowaki. 1993. Sitedirected mutagenesis of the juxtamembrane domain of the human insulin receptor. J. Biol. Chem. 268:16610-16622.

15. Berget, S.M. 1995. Exon recognition in vertebrate splicing. J. Biol. Chem. 270:2411-2414

16. Will, K., T. Dörk, M. Stuhrmann, T. Meitinger, R. Bertele-Harms, B. Tümmler, and J. Schmidtke. 1994. A novel exon in the cystic fibrosis transmembrane conductance regulator gene activated by the nonsense mutation E92X in airway epithelial cells of patients with cystic fibrosis. J. Clin. Invest. 93:18521859.

17. Dietz, H.C., D. Valle, C.A. Francomano, R.J. Kendzior, Jr., R.E. Pyeritz, and G.R. Cutting. 1993. The skipping of constitutive exons in vivo induced by nonsense mutations. Science. 259:680-683.

18. Cáceres, J.F., S. Stamm, D.M. Helfman, and A.R. Krainer. 1994. Regulation of alternative splicing in vivo by overexpression of antagonistic splicing factors. Science. 265:1706-1709.

19. Goguel, V., and M. Rosbash. 1993. Splice site choice and splicing efficiency are positively influenced by pre-mRNA intramolecular base pairing in yeast. Cell. 72:893-901.

20. Wu, J.Y., and T. Maniatis. 1993. Specific interactions between proteins implicated in splice site selection and regulated alternative splicing. Cell. 75: 1061-1070.

21. Krook, A., L. Brueton, and S. O'Rahilly. 1993. Homozygous nonsense 
mutation in the insulin receptor gene in infant with leprechaunism. Lancet. 31: 277-278.

22. Rolfini, R., and G. Cabrini. 1993. Nonsense mutation R1162X of the cystic fibrosis transmembrane conductance regulator gene does not reduce messenger RNA expression in nasal epithelial tissue. J. Clin. Invest. 92:26832687.

23. Winnard, A.V., J.R. Mendell, T.W. Prior, J. Florence, and A.H.M. Burghes. 1995. Frameshift deletions of exon 3-7 and reveretant fiberes in Duchenne muscular dystrophy: mechanisms of dystrophin production. Am. J. Hum. Genet. 56:158-166.

24. Feener, E.P., J.M. Backer, G.L. King, P.A. Wilden, X.J. Sun, C.R. Kahn, and M.F. White. 1993. Insulin stimulates serine and tyrosine phosphorylation in the juxtamembrane region of the insulin receptor. J. Biol. Chem. 268:1125611264.

25. Kaburagi, Y., R. Yamomoto-Honda, K. Tobe, K. Ueki, M. Yachi, Y. Akanuma, R.M. Stephens, D. Kaplan, Y. Yazaki, and T. Kadowaki. 1995. The role of the NPXY motif in the insulin receptor in tyrosine phosphorylation of insulin receptor substrate-1 and Shc. Endocrinology. 136:3437-3443.

26. Taouis, M., R. Levy-Toledano, P. Roach, S.I. Taylor, and P. Gordon. 1994. Structural basis by which a recessive mutation in the $\alpha$-subunit of the insulin receptor affects insulin binding. J. Biol. Chem. 269:14912-14918. 